\title{
Osteomielitis en cúbito tratado con criocirugía
}

\author{
Ulna osteomyelitis treated with cryosurgery \\ Aramíz López Durán, * Rubén Lechuga González ${ }^{\ddagger}$ \\ *Médico adscrito al Servicio de Ortopedia; ${ }^{\star}$ Médico residente de quinto año. Alta Especialidad en Ortopedia Pediátrica. Instituto Nacional de Pediatría.
}

\begin{abstract}
Resumen
La infección musculoesquelética en los niños exhibe una amplia gama de afecciones y presentaciones en la clínica, que pueden ocurrir de manera aislada o combinadas, incluyendo formas complejas o sistémicas. Estas condiciones incluyen osteomielitis (aguda, subaguda y crónica), discitis, artritis séptica, absceso, celulitis. La manifestación clínica de los niños con cualquiera de dichas particularidades podría tener características muy similares para crear desde un dilema diagnóstico inicial hasta una historia completa; se requiere de un examen físico, pruebas de laboratorio, radiografías simples, y quizá se puedan requerir imágenes avanzadas, por ejemplo resonancia magnética, tomografía computada, o gammagrama óseo con radioisótopo marcado. La osteomielitis requiere de una atención integral por varias especialidades médicas, que suelen estar involucradas en la evaluación y cuidado de estos padecimientos. Es esencial la sincronización y trabajo en equipo entre el servicio de ortopedia e infectología a fin de lograr el mejor resultado en estos pacientes. La curación de la osteomielitis en grado crónico plantea un desafío y una amplia experiencia clínica es esencial para abordar adecuadamente esta grave complicación en los enfermos pediátricos. En consecuencia, el objetivo de este estudio es relatar la experiencia y presentar los resultados del tratamiento de esta patología empleando terapia antibiótica, criocirugía y vidrios bioactivos. Se expone el caso de un paciente femenino de 17 años de edad con una osteomielitis arraigada en cúbito.
\end{abstract}

Palabras clave: Osteomielitis, cúbito, criocirugía, manejo quirúrgico.

\section{Abstract}

Musculoskeletal infection in children exhibits a wide range of conditions and clinical presentations, which can occur singly or in combination, including complex or systemic forms. These conditions include osteomyelitis (acute, subacute, and chronic), discitis, septic arthritis, abscess, cellulitis. The clinical presentation of children with any of these conditions may have sufficient similar characteristics to create from an initial diagnosis of dilemma up to a complete history; physical examination, laboratory tests, plain radiographs, and advanced imaging can be performed. A wide variety of medical specialties is often involved in the evaluation and treatment of such conditions. The link between the orthopedics and infectology services is essential to achieve the best results in these patients. The treatment of chronic osteomyelitis is challenging, and extensive clinical experience is essential to adequately address this serious complication in pediatric patients. Consequently, the objective of this study is to narrate our experience and present results of the treatment of this pathology, using cryosurgery and bioactive glass. The case of ulna osteomyelitis in a 17-year-old patient is presented.

Keywords: Osteomyelitis, ulna, cryotherapy, surgical management.

\section{Introducción}

La osteomielitis (término propuesto por Lannelongue) es el proceso inflamatorio de la parte medular y córtico esponjosa del hueso, a consecuencia de un contagio causado por agentes biológicos (bacterias, hongos, etc.) que los comprometen, y a los que llegan tanto por vía hemática (en general arterial) como por inoculación externa (frecuentemente por fractura expuesta) o por contigüidad (en los huesos que limitan cavidades naturales infectadas: sinusitis, mastoiditis, etcétera). Entre

Correspondencia:

Rubén Lechuga González

E-mail: rvbenlec@gmail.com

Recibido: 06-03-2021. Aceptado: 14-04-2021.

Citar como: López DA, Lechuga GR. Osteomielitis en cúbito tratado con criocirugía. Orthotips. 2021; 17 (3): 167-173. https://dx.doi. org/10.35366/100628 
los agentes bacterianos, los más frecuentes son el Staphylococcus aureus, responsable de $80 \%$ de los casos, el Staphylococcus albus y el estreptococo $\beta$ hemolítico, estos dos últimos, causantes de $11 \%$ de los casos, ${ }^{1}$ sin embargo, es sabido que una amplia variedad de gérmenes puede causar esta contaminación por vía hematógena, de esa manera, además de estos patógenos, se podrían encontrar otras entidades en inoculaciones directas como son las fracturas expuestas.

En las osteomielitis crónicas, las lesiones de vascularización y necróticas en los huesos se muestran

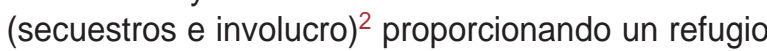
para las bacterias, disminuyendo la eficiencia en el tratamiento y convirtiéndose en una fuente de recurrencia, redundando en pronósticos sombríos.

La infección musculoesquelética en los niños se exhibe en una amplia gama de signos y síntomas que pudiesen ocurrir de forma aislada o en combinación, incluyendo formas complejas o sistémicas. Estas condiciones incluyen osteomielitis (aguda, subaguda y crónica), discitis, artritis séptica, absceso (superficial o profundo), celulitis, fascitis, linfangitis y linfadenitis. Los niños con infección musculoesquelética pueden tener una participación adicional de otros sistemas, comprendiendo trombosis venosa profunda (TVP), embolia pulmonar séptica, neumonía, empiema, endocarditis, bacteriemia y choque séptico. ${ }^{3}$ La presentación clínica con cualquiera de esas peculiaridades podría tener características suficientemente similares para crear un problema diagnóstico. Se podrían realizar exámenes físicos, pruebas de laboratorio, radiografías simples e imágenes avanzadas, por lo que son atendidos por varias disciplinas médicas las cuales suelen estar involucradas en el diagnóstico y atención de dicha patología.

Los pacientes con fracturas expuestas son mucho más propensos a desarrollar infecciones óseas posteriores, pese a recibir un tratamiento adecuado y oportuno. El primer paso al asistir a una persona con una fractura es definir si es cerrada o abierta. Si la fractura es expuesta se usa la clasificación de Gustillo-Anderson creada en 1976, la cual predice el riesgo de inoculación en base al grado de lesión de los tejidos, contaminación de la herida y tipo de fractura. ${ }^{4}$

Dependiendo del estado de exposición del hueso, es posible estimar el riesgo que presenta el paciente a sufrir una posterior infección ósea, como se muestra en la Tabla 1. En quirófano se reclasificará con base en el grado de lesión de los tejidos, con posterior desbridamiento extenso de los mismos y lavado con solución fisiológica de 3 a 10 litros a baja presión, en función de la extensión, gravedad y contaminación de la herida. En función de la severidad del traumatismo podrá programarse un aseo quirúrgico cada 48 horas. En cuanto a la duración del plan antimicrobiano, hay un consenso de indicarlo por vía intravenosa por tres a 21 días y, en fracturas complejas que requieren plan de limpiezas quirúrgicas seriadas, extenderlo por tres semanas.

La estabilización de las fracturas abiertas puede ser transitoria o definitiva, en pacientes traumatizados graves el uso de fijadores externos disminuye el riesgo de contagio en la etapa de inmunodepresión e inflamación de las primeras dos a tres semanas. En un segundo tiempo se fijan definitivamente; si el estado del enfermo aún no permite esta maniobra se recomienda rotar de posición los fijadores externos.

En la atención de la osteomielitis en grado crónico es necesario el desbridamiento adecuado. Desafortunadamente, este tratamiento a menudo resulta en un defecto óseo, poco vascularizado, un espacio muerto (involucro o secuestro). ${ }^{5}$ El contagio bacteriano también es capaz de causar acidosis local, que conduce a la disolución de la matriz ósea. ${ }^{6}$ Se han utilizado muchos métodos diferentes a fin de tratar el defecto óseo y la infección, incluidos los injertos heterólogos, injertos óseos vascularizados, polimetilmetacrilato impregnado con antibiótico en perlas, trifosfato cálcico en perlas, formación de granulación según la técnica de Papineau y la técnica de Masquelet ${ }^{7}$ o reconstrucción ósea con técnica llizarov; en tejidos blandos es necesario la realización de colgajos músculo cutáneos.

Las bacterias también tienen métodos sofisticados para la formación de biopelículas (biofilm), lo que dificulta el abordaje con agentes antimicrobianos, ${ }^{8} \mathrm{el}$

Tabla 1: Clasificación de Gustillo-Anderson y riesgo de infección.

\begin{tabular}{|c|c|c|}
\hline $\begin{array}{l}\text { Tipo de } \\
\text { clasificación }\end{array}$ & Gustilo-Anderson & $\begin{array}{l}\text { Infección } \\
\quad \%\end{array}$ \\
\hline 1 & Herida limpia, puntiforme $<1 \mathrm{~cm}$ & 1.8 \\
\hline ॥ & $\begin{array}{l}\text { Herida }>1 \mathrm{~cm} \text { con escaso daño de tejidos y } \\
\text { moderado grado de contaminación }\end{array}$ & 3.3 \\
\hline III A & $\begin{array}{l}\text { Extensa lesión de partes blandas }>10 \mathrm{~cm} \text {, } \\
\text { pero permite el cierre de planos por encima } \\
\text { del hueso fracturado }\end{array}$ & 5.0 \\
\hline III B & $\begin{array}{l}\text { El compromiso y pérdida de tejidos blandos y } \\
\text { periostio no permite el cierre de planos }\end{array}$ & 12.0 \\
\hline III C & Cualquier fractura que asocie lesión arterial & 16.0 \\
\hline
\end{tabular}



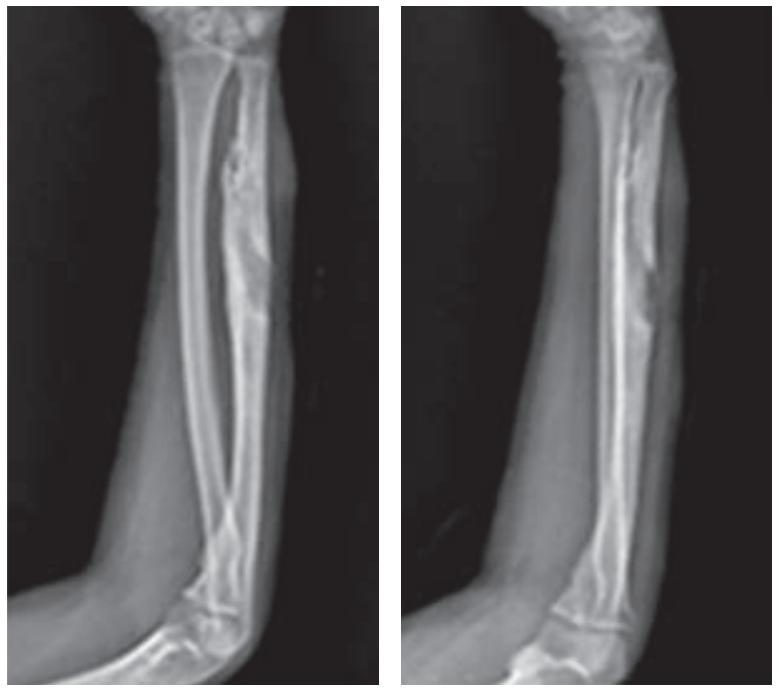

Figura 1: Radiografías iniciales, proyección AP y lateral de antebrazo derecho en las cuales se observan lesiones osteolíticas en cúbito diafisario, en la unión del tercio medio y distal, con evidencia de solución de continuidad ósea.

uso de injerto óseo en la curación de la osteomielitis es, por lo tanto, no recomendado.

Los vidrios bioactivos (BAG-S53P4) son sustitutos óseos osteoconductores biocompatibles sintéticos con capacidad de unión ósea, con propiedades antibacterianas y promotoras de las angiogénesis. ${ }^{9,10} \mathrm{Se}$ cuenta con guías de práctica clínica para el manejo de pacientes con fracturas expuestas, así como dirigidas a aquellos que cursan con infecciones óseas agudas.

Sin embargo, no existen protocolos que aborden el manejo de la osteomielitis crónica en niños; se reporta el caso de un menor con osteomielitis persistente secundaria a una fractura expuesta de cúbito, la cual no recibió tratamiento oportuno, y posteriormente fue tratado en el servicio utilizando la criocirugía y el uso del vidrio denominado bioactivo, como parte del arsenal empleado en la curación de estas contaminaciones óseas.

\section{Presentación del caso}

Paciente femenino de 17 años de edad, quien es enviada al Servicio de Urgencias de esta unidad por exhibir traumatismo en antebrazo derecho. Inició su padecimiento actual alrededor de un mes y medio previo a la valoración, con caída desde su plano de sustentación, contundiendo en miembro superior derecho en hiperextensión de codo y muñeca y carga axial, con presencia de dolor, limitación funcional y sangrado en tercio medio de antebrazo derecho, razón por la que entonces acudió con un médico, quien realizó en su consultorio lavado mecánico en varias ocasiones e indicó curación diaria de la herida; sin embargo, ella reportó aumento de dolor, y aproximadamente un mes posterior a la lesión presentó secreción a través de la herida, la cual aumentó en cantidad, motivo por el cual acude a valoración a la unidad.

A su ingreso al Servicio de Urgencias es valorada por el Servicio de Ortopedia; se lleva a cabo una exploración física en la cual se reporta femenino, ectomorfa, neurológicamente íntegra, esqueléticamente con extremidad superior derecha con lesión dermocutánea de casi cuatro centímetros de longitud, con eritema perilesional, con presencia de exposición ósea del fragmento proximal del cúbito, así como secreción purulenta fétida, sin características específicas.

En esta valoración se solicitan radiografías anteroposterior (AP) y lateral de antebrazo derecho (Figura 1) en las cuales se observan lesiones osteológicas en cúbito diafisario, en la unión del tercio medio y distal, con evidencia de solución de continuidad ósea.

Al completar el protocolo preoperatorio, ayuno y laboratorios, ingresa a quirófano a fin de realizar lavado quirúrgico, desbridamiento, junto con curetaje y cierre de herida quirúrgica, lo cual se llevó a cabo sin complicaciones, al iniciar el evento quirúrgico se toman muestras para cultivo. Posteriormente se inicia con antibioticoterapia a base de cefalotina.

Con el resultado del cultivo, es valorada por el Servicio de Infectología con las conclusiones de los mismos, en los cuales se reporta S. aureus y $\mathrm{C}$. perfringens; se indica la cobertura antimicrobiana con cefalosporina de tercera generación con espectro gramnegativos, más cefalosporina de primera gene-

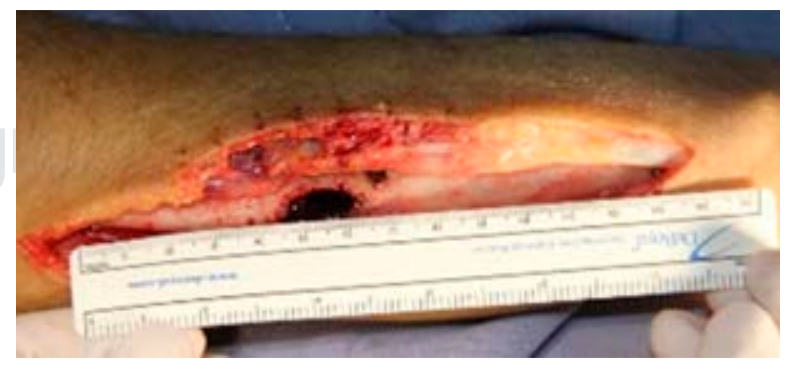

Figura 2: Imagen transoperatoria, con exposición de cúbito con presencia de lesión en su tercio medio. 
ración con espectro a $S$. aureus, meticilino sensible más nitroimidazol con espectro a anaerobios por aislamiento mencionados, por lo que se agrega ceftriaxona y metronidazol al esquema antibiótico.

Se solicitó una gammagrafía ósea, la cual reportó hipercaptación en antebrazo derecho. Se llevó a cabo el segundo procedimiento quirúrgico en el cual se realizó resección de segmento decúbito, colocación de criocirugía a lecho y al segmento óseo, así como recolocación del fragmento óseo y fijación del mismo con clavillo Kirschner. Se realizó el abordaje lateral decúbito en sitio de indicios previo, se amplían abordajes a distal y proximal (Figura 2), se diseca por planos hasta encontrar tejido óseo, se retira periostio en su totalidad en sentido medial y lateral se procede fijar articulación radio cubital distal con clavillo de Kirchner, se realiza osteotomía de $13.5 \mathrm{~cm}$ de segmento óseo, se reseca para aplicar crioterapia, a lecho y segmento óseo con $-80^{\circ}$ por 10 minutos (Figuras 3 y 4 ), se coloca en nitrógeno líquido por 10 minutos, posteriormente se procede al descongelamiento de fragmento con solución fisiológica (Figura 5) se procede a colocar fijación centro medular con clavillo de Kirschner, se toman radiografías de control y se procede a cierre por planos (Figura 6).

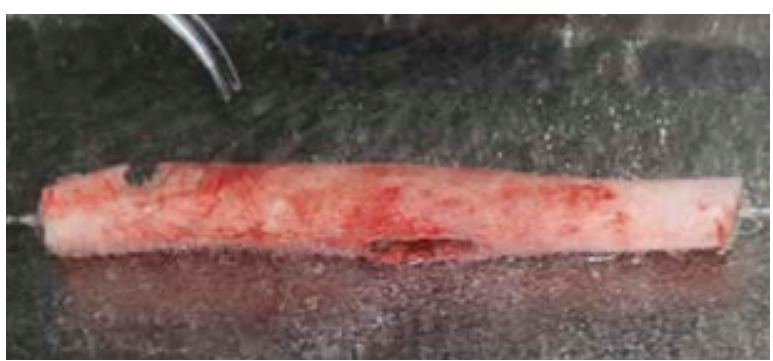

Figura 3: Fotografía transquirúrgica tras la resección del segmento de cúbito, se realiza sumersión del mismo en nitrógeno líquido a $-80^{\circ} \mathrm{C}$ por 10 minutos.

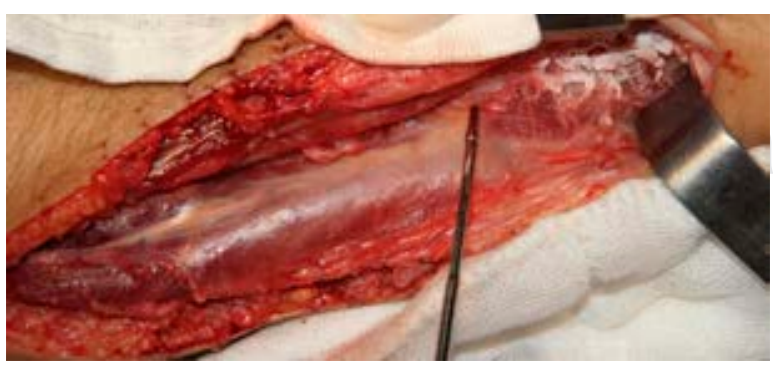

Figura 4: Se realiza congelamiento sobre tejidos blandos circundantes a la lesión previamente resecada.

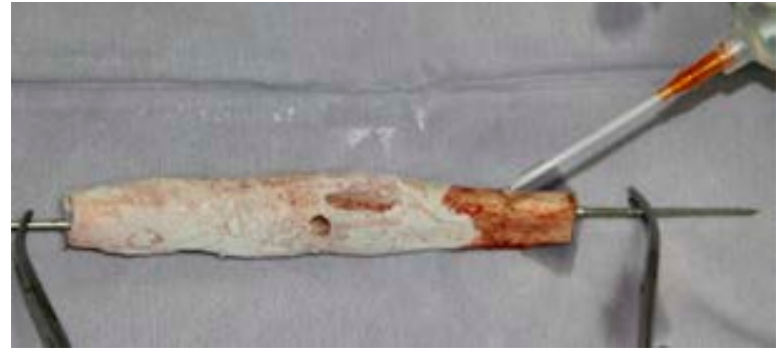

Figura 5: Se realiza descongelamiento de fragmento con solución fisiológica para su posterior recolocación y fijación del mismo.

Se obtiene resultado de patología del primer cultivo, en el cual se diagnostica osteomielitis crónica. A su egreso continúa su control en consulta externa de Ortopedia e Infectología, donde reportan que se completó el esquema antibiótico de seis semanas (2 IV) y 4 (VO) con mejoría clínica y laboratorial evidente.

Se retiran clavillos Kirschner en consulta externa y se coloca aparato circular braquipalmar de fibra de vidrio. Se cuenta con radiografías de control, en las cuales de observan datos de consolidación ósea grado III por la clasificación de Montoya. Pasa en un tercer tiempo a quirófano y en este procedimiento se realiza curetaje, junto con colocación de vidrio bioactivo S53P4 en cúbito (Figura 7); el cual se lleva a cabo sin complicaciones, y es egresada.

En consulta externa, cuatro semanas posteriores a la cirugía, a los rayos $\mathrm{X}$ se evidencia adecuada osteointegración de ese vidrio S53P4 (Figura 8), así como clínicamente sin presencia de dolor, rubor, aumento de volumen, con arcos de movilidad, pronosupinación completa, fuerza y tono preservado.

\section{Discusión}

La osteomielitis, descrita por primera vez por Chassaignac en 1852, es causada por diversos microorganismos y crea un proceso inflamatorio en el hueso, que a menudo se acompaña de destrucción ósea. ${ }^{11}$ La mayoría de las veces es causada por un traumatismo, pero cualquier tipo de cirugía de huesos o tejidos blandos donde los patógenos son capaces de ingresar al hueso podrían causar la infección; sin embargo, puede aparecer mediante otras vías de acceso.

La osteomielitis aguda es una infección caracterizada por edema, disminución local del suministro de sangre y formación de pus. No tratado, o debido al fracaso del tratamiento, la infección pudiese progresar 
a una fase más arraigada, con la formación de un área de hueso muerto desvascularizado, un secuestro.

En el cuidado de la osteomielitis crónica el desbridamiento adecuado es obligatorio, desafortunadamente, este tratamiento a menudo resulta en un defecto óseo grande, mal vascularizado, un espacio muerto que no mejora pese a la administración de antibióticos.

La contaminación bacteriana también puede causar acidosis local, que conduce a la disolución

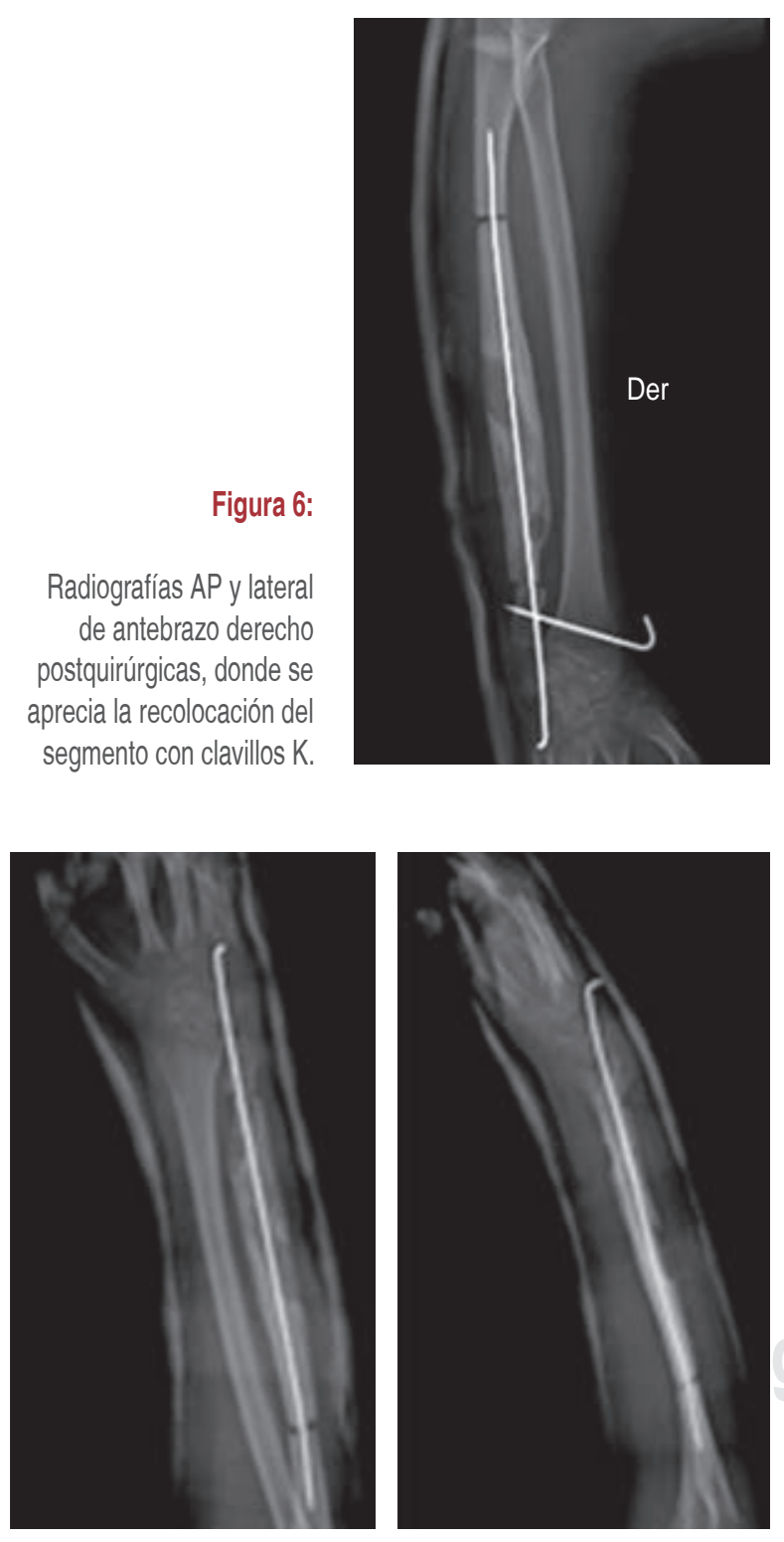

Figura 7: Radiografías AP y lateral de antebrazo derecho postquirúrgicas del tercer tiempo quirúrgico, donde se realiza curetaje, junto con colocación de vidrio bioactivo S53P4 en cúbito.

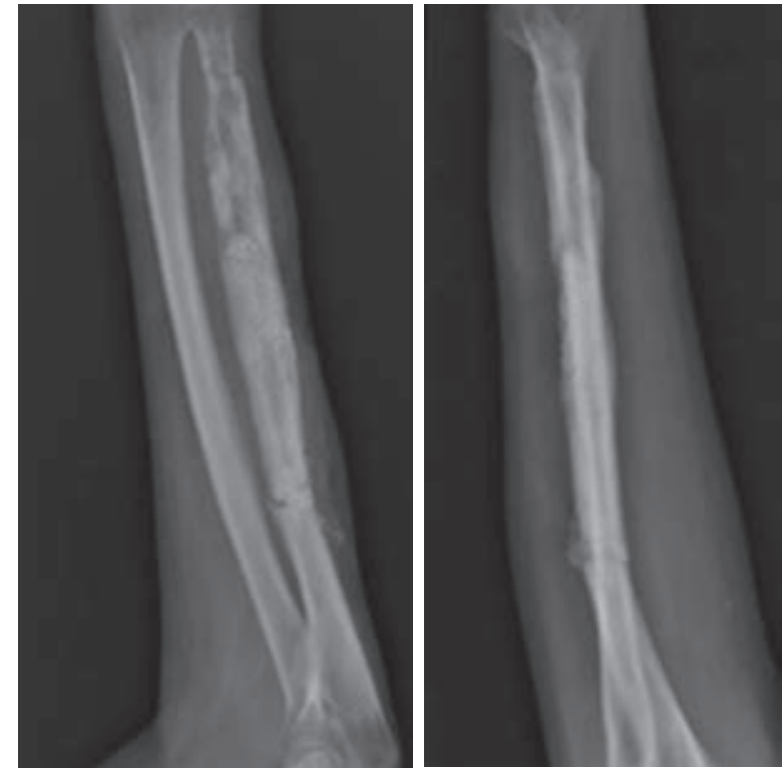

Figura 8: Radiografía de control a las cuatro semanas del último evento quirúrgico donde se evidencia adecuada osteointegración de ese vidrio S53P4.

de la matriz ósea mineral. ${ }^{6}$ Se han utilizado muchos métodos diferentes buscando tratar el hueso, el defecto y la infección, incluidos los injertos óseos vascularizados libres, locales colgajos musculares, polimetilmetacrilato impregnado con antibiótico en perlas, formación de granulación según la técnica de Papineau y la técnica de Masquelet. ${ }^{7,12}$

El Staphylococcus aureus y los bacilos gramnegativos son los patógenos más comúnmente involucrados, ${ }^{13}$ la colonización bacteriana del tejido del huésped o materiales implantados es promovida por la capacidad de las bacterias para producir adhesinas específicas de proteínas en sus superficies, que se unen con los componentes de la proteína del huésped, como el fibrinógeno, fibronectina y colágeno. Las bacterias también tienen métodos sofisticados para comunicación a través de compuestos similares a hormonas en biopelículas, haciendo que el tratamiento con agentes antimicrobianos sea difícil. ${ }^{14,15}$

El uso de sustitutos de injerto óseo en la atención de la osteomielitis es, por lo tanto, no recomendado.

Los vidrios bioactivos (BAG) son osteoconductores biocompatibles sintéticos para sustitutos óseos, con capacidad de unión ósea y documentadas propiedades antibacterianas y promotoras de la angiogénesis. ${ }^{16}$

Estudios previos sobre rinitis atrófica, un trastorno purulento crónico a menudo causado por Klebsiella 
ozaenae y difícil de tratar, han demostrado que el BAG-S53P4 no favorece la adhesión o colonización de K. ozaenae en su superficie. Además, K. ozaenae no puede formar biopelículas en el BAGS53P4. ${ }^{17}$

El uso de la criocirugía se reporta en la literatura en la parte de abordajes de afección de índole oncológica, sin embargo, en este evento fue empleada como elemento del tratamiento de una patología de origen infeccioso, bajo el mismo precepto de los efectos obtenidos sobre las células sometidas a estas bajas temperaturas.

La crioterapia utiliza nitrógeno líquido y dióxido de carbono, en el papel de agentes de congelación para destruir tejido patológico a bajas temperaturas, y elimina las lesiones durante el proceso de curación. ${ }^{18,19}$ La cirugía por congelación es un tratamiento reconocido para tumores, lesiones precancerosas y quistes. ${ }^{20-22} \mathrm{Al}$ principio, esta crioterapia se aplicaba sólo a tumores malignos de los labios y lesiones en la cavidad oral, ${ }^{23}$ pero desde entonces se ha aplicado en dermatología, oftalmología, otorrinolaringología y cirugía general. Además, se cree que la criocirugía es indolora, porque en los nervios la transmisión se bloquea inmediatamente por la baja temperatura. ${ }^{18}$

La muerte de las células tisulares se produce a temperaturas iguales o inferiores a $20^{\circ} \mathrm{C},{ }^{18}$ y la cirugía por congelación puede reducir con rapidez la lesión a temperaturas por debajo de $20^{\circ} \mathrm{C}$.

La temperatura de la zona del daño se recupera con celeridad cuando se detiene la criocirugía. ${ }^{18,19}$ Este cambio abrupto de temperatura promueve la formación de cristales de hielo en el compartimento extracelular e intracelular. Un gradiente osmótico provocado por los cristales de hielo extracelulares genera la pérdida de agua intracelular.

Esto da lugar a toxicidad debido a anomalías de las vías intracelulares y electrolitos extracelulares y posteriormente, muerte celular. ${ }^{18}$

Los pacientes presentan pocas complicaciones después de la criocirugía, por ejemplo hiperemia, hinchazón, dolor leve y erosión, pero normalmente se pueden curar sin problemas. ${ }^{18,19}$ Por lo tanto, este tipo de cirugía se considera un método sencillo y seguro para la curación.

Es por ello que se emplea como parte del tratamiento en una osteomielitis de nivel crónico y ha ayudado a tener buenos resultados en esta paciente.

\section{Conclusiones}

Se narra un caso de osteomielitis crónica en cúbito, tratada con criocirugía y colocación de vidrio bioactivo. Se plasman en este trabajo los resultados clínicos y radiológicos de una paciente, los cuales fueron satisfactorios.

No se cuenta con un consenso que marque la pauta en el tratamiento de este tipo de complicaciones, es por ello que se transcribe la experiencia.

Aunada a los lavados quirúrgicos, desbridamiento y antibioticoterapia, se ofrece la cirugía por congelación como un arma más en la reparación de la osteomielitis en grado crónico en huesos largos, así mismo, la colocación de vidrio bioactivo fue parte de este arsenal que rindió resultados favorables en la paciente.

El uso de estas dos herramientas en casos de osteomielitis crónica, sumado a lo previamente descrito, puede emplearse en estos casos, por lo que una serie mayor de pacientes seria indispensable para valorar de mejor manera los resultados.

\section{Referencias}

1. Lanza G. Trattato di anatomía e istologia patológica. Editore, Padova, 1975, T II, 12: 636.

2. Paluska SA. Osteomyelitis. Clin Family Prac. 2004; 6: 127-156.

3. Riise OR, Kirhus E, Handeland KS, Flato B, Reiseter T, Cvancarova $\mathrm{M}$, et al. Childhood osteomyelitis-incidence and differentiation from other acute onset musculoskeletal features in a population-based study. Pediatrics. 2008; 8: 45-55.

4. Zalavras CG. Prevention of infection in open-fractures. Infect Dis Clin North Am. 2017; 31: 339-352.

5. Parsson B, Strauss E. Surgical management of chronic osteomyelitis. Am J Surg. 2004; 188: 57-66.

6. Konttinen YT, Tagaki M, Mandelin J, Lassus J, Salo J, Ainola $\mathrm{M}$, et al. Acid attack and cathepsin $\mathrm{K}$ in bone resorption around total hip replacement prosthesis. J Bone Miner Res. 2001; 16: 1780-1786.

7. Powerski M, Maier B, Frank J, Marzi I. Treatment of severe osteitis after elastic intramedullary nailing of a radial bone shaft fracture by using cancellous bone graft in Masquelet technique in a 13-year-old adolescent girl. J Pediatr Surg. 2009; 44: 17-19.

8. Lew DP, Waldfogel FA. Osteomyelitis. Lancet. 2004;364: 369-379.

9. Andersson $\mathrm{OH}$, Kangasniemi I. Calcium phosphate formation at the surface of bioactive glass in vitro. J Biomed Mater Res. 1991; 24: 1019-1030.

10. Day RM. Bioactive glass stimulates the secretion of angiogenetic growth factors and angiogenesis in vitro. Tissue Eng. 2005; 11: 768-777.

11. Lazzarini L, Mader JT, Cahoun JH. Osteomyelitis in long bones. J Bone Joint Surg. 2004; 86-A: 2305-2318.

12. Andersson $\mathrm{OH}$, Karlsson $\mathrm{KH}$, Kangasniemi K. Calcium phosphate formation at the surface of bioactive glass in vivo. J Non-Cryst Solids. 1990; 119: 290-296.

13. Farah CS, Savage NW. Cryotherapy for treatment of oral lesions. Aust Dent J. 2006; 51: 2-5.

14. Haartemann-Heurtier A, Senneville E. Diabetic foot osteomyelitis. Diabetes Metab. 2008; 34: 87-95.

15. Stoor P, Soderling E, Grenman R. Interactions between the bioactive glass S53P4 and the atrophic rhinitis-associated 
microorganism Klebsiella ozaenae. J Biome Mater Res Appl Biomater. 1999; 48: 869-874.

16. Kujan O, Azzeghaiby SN, Tarakji B, Abuderman A, Sakka S. Cryosurgery of the oral and peri-oral region: a literature review of the mechanism, tissue response, and clinical applications. J Investig Clin Dent 2013; 4: 71-77.

17. Yeh CJ. Treatment of verrucous hyperplasia and verrucous carcinoma by shave excision and simple cryosurgery. Int $\mathrm{J}$ Oral Maxillofac Surg. 2003; 32: 280-283.

18. Prasad M, Kale TP, Halli R, Kotrashetti SM, Baliga SD. Liquid nitrogen cryotherapy in the management of oral lesions: a retrospective clinical study. J Maxillofac Oral Surg. 2009; 8: 40-42.

19. Farah CS, Koelmeyer N, Kaney A, Simanovic B. Nitrous oxide cryotherapy for the management of benign lesions of the oral cavity. J Oral Pathol Med. 2019; 48: 611-618.
20. Emmings FG, Koepf SW, Gage AA. Cryotherapy for benign lesions of the oral cavity. J Oral Surg. 1967; 25: 320-326.

21. Gage AA. Cryotherapy for oral cancer. JAMA. 1968; 204: 565569.

22. Chandler JR. Cryosurgery for recurrent carcinoma of the oral cavity. Arch Otolaryngol. 1973; 97: 319-321.

23. Lindgren G, Larko O. Cryosurgery of eyelid basal cell carcinomas including 781 cases treated over 30 years. Acta Ophthalmol. 2014; 92: 787-792.

\section{Conflicto de intereses}

No se tiene conflicto de intereses. 